\title{
Effect of Electrolyte Concentration in Process Water on Flocculation
}

\author{
Jose Moreno-Chavez ${ }^{1,2 *}$ \\ ${ }^{1}$ Norman B. Keevil Institute of Mining Engineering, University of British Columbia, Vancouver, Canada. \\ ${ }^{2}$ Escuela Superior Politécnica del Litoral, ESPOL, Facultad de Ingeniería en Ciencias de la Tierra, Campus \\ Gustavo Galindo Km. 30.5 Vía Perimetral, P.O. Box 09-01-5863, Guayaquil, Ecuador.
}

*Corresponding author: Jose Moreno-Chavez, email: josmoren@espol.edu.ec

Received October 19 $9^{\text {th }}, 2019$; Accepted October 22 ${ }^{\text {th }}, 2019$.

DOI: http://dx.doi.org/10.29356/jmcs.v64i1.720

\begin{abstract}
The effect of electrolyte concentration and potential determining ions on the coagulation and flocculation of illite, dolomite, and illite-dolomite mixture suspensions was investigated. Electrokinetic measurements, settling rate tests, and viscosity measurements were performed to examine the stability of these mineral suspensions and to characterize flocculants under various physico-chemical conditions. Two flocculants: A-100 anionic polyacrylamide (PAM) and polyethylene oxide (PEO) were employed.

The tests revealed that polyethylene oxide does not flocculate dolomite under any tested conditions. Viscosity results corroborated that the conformation of PAM macro- molecules in water is very sensitive to electrolyte concentration; on the other hand, the conformational state of PEO macromolecules is not affected by ionic strength. The intrinsic viscosity measurements suggest that the unattainable flocculation of dolomite suspensions with PEO must result from poor adsorption of this flocculant onto dolomite particles. In both tested cases, with PAM and PEO, the relationship between coagulation and flocculation was not confirmed.
\end{abstract}

Keywords: Coagulation; flocculation; electrolyte solutions; intrinsic viscosity.

Resumen. Se investigó el efecto de la concentración electrolítica y iones determinantes de potencial en la coagulación y floculación de suspensiones de ilita, dolomita y mezcla de ilita-dolomita. Mediciones electrocinéticas, ensayos de velocidad de sedimentación, y mediciones de viscosidad fueron realizadas para examinar la estabilidad de estas suspensiones minerales y caracterizar floculantes bajo varias condiciones fisicoquímicas. Se empleó dos floculantes: A-100 poliacrilamida aniónica (PAM) y óxido de polietileno (PEO). Los experimentos revelaron que el óxido de polietileno no flocula la dolomita bajo ninguna condición empleada. Los resultados de viscosidad corroboraron que la conformación de las macromoléculas PAM en agua es sensible a la concentración electrolítica; por otro lado, el estado conformacional de las macromoléculas de PEO no se ve afectado por la fuerza iónica. Las mediciones de viscosidad intrínseca sugieren que la floculación inalcanzable de las suspensiones de dolomita con PEO debe ser resultado de una mala adsorción de este floculante en las partículas de dolomita. En ambos casos probados, con PAM y PEO, no se confirmó la relación entre coagulación y floculación.

Palabras clave: Coagulación; floculación; solución electrolítica; viscosidad intrínseca. 


\section{Introduction}

The mineral processing plant flowsheet includes four distinct unit operations (Fig. 1): comminution (crushing and grinding) and classification, separation (flotation), product dewatering (solid/liquid separation), and water clarification. To improve solid/liquid separation operations (both thickening and filtration) the industry applies flocculants. These are water- soluble polyelectrolytes. Since the process water that is used in flotation, before its reuse, is treated in the product dewatering and water clarification unit operations, the use of seawater in flotation also requires the same treatment in which flocculants are applied. The effect of the salt concentration on flocculation is as important as on flotation.

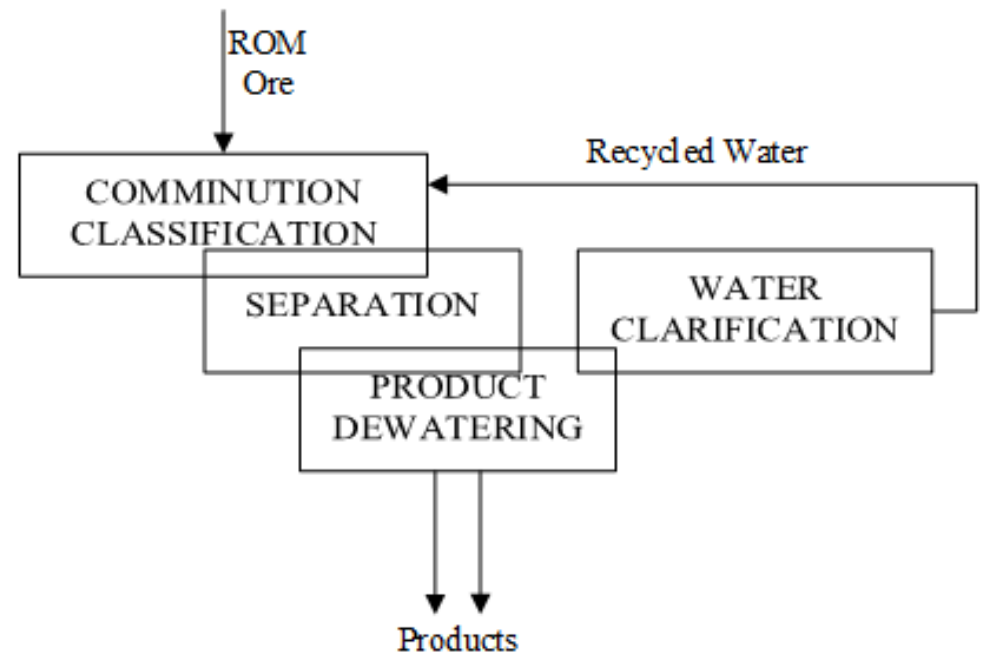

Fig. 1. Closed water circuit in the modern mineral processing plant.

In the solid/liquid separation unit operations, a flocculation process is used to aid particle settling and filtration. Polymeric flocculants are hydrophilic colloids with high molecular weight, their solubility in water is owing to solvation of the polar (ionic and non-ionic) groups being strong enough to prevail over the van der Waals cohesive forces between the polymer segments [1].

It is generally accepted that aggregation caused by polymeric flocculants results from bridging mechanism [2]. It is important to ascertain that adsorption and flocculation are not separate sequential processes but occur simultaneously [3]. Polymeric flocculants can be classified based on one or more of their properties, such as molecular weight, functional group, charge, chemical structure, or origin [4]. It is known that different polyacrylamide flocculants have different molecular weights and different degrees of anionicity [5]. Several studies have shown that high molecular weight anionic polymers, such as polyacrylamide, are commonly used to flocculate negatively charged clays [6-8].

As indicated by Kitchener [9], polymeric flocculants have the ability to produce larger, stronger flocs than those aggregates obtained by inorganic coagulants. They may be applied either after destabilizing the suspension via coagulation, or without prior destabilization:

$$
\begin{aligned}
& \text { Stable suspension } \Rightarrow \text { coagulation } \Rightarrow \text { flocculant addition } \Rightarrow \text { flocculation. } \\
& \text { Stable suspension } \Rightarrow \text { flocculant addition } \Rightarrow \text { flocculation. }
\end{aligned}
$$

Nevertheless, method (a) is always better since flocculants are not very effective in treating stable suspensions [10]. Consequently, destabilization of a fine particle suspension can be accomplished by 
suppressing the electrical repulsion by double layer compression (coagulation), the treatment that improves flocculation. A recent study by Onen and Gocer [11], has shown that coagulation plus flocculation results in better sedimentation efficiency rather than single methods. However, there are also studies that contradict the previous statements. As indicated by Rubio [12], coagulation of the particles before flocculation is not always enough condition for obtaining effective flocculation.

In modern processing plants water is recycled and reused. The recycled process water is a high electrolyte concentration medium. Concentration of these solutions may be as high as $1 \mathrm{M} \mathrm{NaCl}$ (e.g. Mount Keith plant in Australia) [13]. Furthermore, in arid regions, the need to save water is necessary and the use of seawater in mineral processing plants is the only sustainable solution in many parts of the world. Sea water is a concentrated solution of $\mathrm{NaCl}$ (about $0.6 \mathrm{M}$ ) with high content of $\mathrm{Ca}^{2+}(0.4 \mathrm{~g} / \mathrm{L}), \mathrm{Mg}^{2+}(1.3 \mathrm{~g} / \mathrm{L})$ and sulfate ions $(2.7 \mathrm{~g} / \mathrm{L})$. When seawater is utilized not only the effect of seawater on flotation but also on solid/liquid separation unit operations must be studied. Since flocculation of mineral suspensions, as was pointed out by Kitchener [9], is more efficient when the suspension is first destabilized by coagulation, the main thesis of this research is that testing coagulation may serve as a convenient method of studying flocculation.

\section{Experimental}

\section{Materials and Methods Sample Preparation}

"Superfloc-A100" polyacrylamide flocculant was provided by CYTEC and polyethylene oxide was acquired from SIGMA-ALDRICH. The viscosity-average molecular weight (MV) was 3,900,000 for A100 (as measured by Ferrera et al. [14]) and 5,000,000 for PEO (provided by the manufacturer). Both flocculants were received as dry, white granules and no further treatment or purification was used. According to Arinaitwe and Pawlik [5] the degree of anionicity of the A-100 flocculant is $10.2 \%$. Sodium hexametaphosphate was provided by VWR International-Canada.

Two minerals, namely dolomite $\left(\mathrm{CaMg}\left(\mathrm{CO}_{3}\right)_{2}\right)$ and illite $\left(\left(\mathrm{K}, \mathrm{H}_{3} \mathrm{O}\right)(\mathrm{Al}, \mathrm{Mg}, \mathrm{Fe})_{2}(\mathrm{Si}, \mathrm{Al})_{4} \mathrm{O}_{10}\right.$

$\left.\left[(\mathrm{OH})_{2},\left(\mathrm{H}_{2} \mathrm{O}\right)\right]\right)$, were chosen for the experiments. These two minerals were selected following the information provided by Friend and Kitchener [15] and the preliminary tests in the Mining Engineering Department at the University of British Columbia (UBC) carried out by Huang et al. [16] and by Yu. [17] The tests include mineral samples (pure minerals) which were acquired from VWR International-Canada, and sample preparation by crushing in a laboratory jaw crusher and dry grinding to below $38 \mu \mathrm{m}$ in a vibratory disc mill. In the next stage, the particle size distribution of the ground material was determined. The volume-average particle size for illite and dolomite were $4.43 \mu \mathrm{m}$ and $4.67 \mu \mathrm{m}$, respectively (Malvern 2000 Mastersizer). The mineralogical composition of the samples, as analyzed by X-ray diffraction is shown in Table 1. X-ray diffraction analysis of a dolomite mineral confirmed that it was pure dolomite. On the other hand, XRD analysis of illite mineral showed that it was a mid-grade illite sample.

Table 1. The main components of the tested minerals (wt. \%).

\begin{tabular}{|c|c|c|c|}
\hline Illite & & Dolomite & \\
\hline Illite & $66.8 \%$ & Dolomite & $99.1 \%$ \\
\hline Quartz & $24.2 \%$ & Quartz & $0.9 \%$ \\
\hline Dolomite & $3.7 \%$ & & \\
\hline Clinochlore & $2.4 \%$ & & \\
\hline Kaolinite & $1.3 \%$ & & \\
\hline Pyrite & $0.7 \%$ & & \\
\hline Rutile & $0.5 \%$ & & \\
\hline Anatase & $0.4 \%$ & & \\
\hline
\end{tabular}




\section{Electrokinetic measurements}

Dolomite samples were used and the required solid concentration in distilled water, $0.001 \mathrm{M} \mathrm{NaCl}$ and $0.01 \mathrm{M} \mathrm{NaCl}$ solutions was $0.005 \mathrm{wt} \%$ of solids ( $5 \mathrm{mg}$ of mineral in $100 \mathrm{~g}$ of solution). The beaker, containing the suspension and a magnetic stirring bar, was put on a magnetic stirrer for conditioning at room temperature for 10 minutes. The $\mathrm{pH}$ of the suspension was measured (natural $\mathrm{pH}$ ) or it was adjusted by the addition of a few drops of $\mathrm{NaOH}$ solutions $(0.1 \mathrm{M}$ or $1 \mathrm{M})$. The equilibration time while stirring was 5 minutes to ensure a stable $\mathrm{pH}$ reading before the measurements. An aliquot was carefully removed by a syringe without disturbing the settled particles at the bottom of the beaker. The cell of the Zeta View PMX 100 instrument was filled with the sample removed from the beaker. This equipment measures the electrophoretic mobility of the particles in suspensions, and zeta potential is calculated using Smoluchowski's equation. Each measurement in the instrument was done in triplicate, and each test was duplicated. Thus, mean zeta values were produced and displayed in the zeta potential plot.

\section{Coagulation tests}

The mineral suspensions (12.5 $\mathrm{g}$ of solids) were prepared by mixing with $175 \mathrm{ml}$ of distilled water or background electrolyte solution at different $\mathrm{pH}$ by a four-bladed flat paddle in a mixing tank for 7 minutes at an impeller speed of $400 \mathrm{rpm}$ using a Lightnin Labmaster mixer. This mixing tank was made of a Plexiglas cylinder and equipped with four baffles. The partly coagulated slurry was then rapidly transferred to a $250-\mathrm{ml}$ graduated cylinder, and the cylinder was inverted once to homogenize the suspension. The mudline was recorded for 5 minutes with the use of a digital camera. The interface settling rate $(\mathrm{cm} / \mathrm{s})$ was calculated from the linear portion of the interface position vs time curve. All settling tests were conducted in duplicate, thus the results presented in this study are average values.

\section{Flocculation tests}

Stock solutions of polymer at concentrations of $0.5 \mathrm{~g} / \mathrm{L}$ were prepared by weighing $0.125 \mathrm{~g}$ of the flocculant in a weighing dish. Distilled water $(250 \mathrm{ml})$ was then added into a $500-\mathrm{ml}$ beaker at room temperature and a magnetic stirrer was used to create a deep vortex. The flocculant granules were carefully added into the sides of the vortex. The top of the beaker was then covered with parafilm. The flocculant solution was left mixing overnight to achieve complete dissolution of the flocculant. To avoid the aging effect, the stock solution was used within 24 hours. It has to be mentioned, an anionic polymer gradually changes its conformation with time from a stretched one to coiled [18]. The mineral suspensions (12.5 g of solids) were prepared by mixing with $175 \mathrm{ml}$ of distilled water or background electrolyte solution at different $\mathrm{pH}$ in a mixing tank at $400 \mathrm{rpm}$ for 3 minutes. The $\mathrm{pH}$ was adjusted using sodium hydroxide $(1 \mathrm{M})$ and hydrochloric acid $(1 \mathrm{M})$. After conditioning, flocculant solution $(25 \mathrm{ml})$ in a burette was added slowly over 4 minutes at a constant rate to the mixing tank and the mixture was stirred at $400 \mathrm{rpm}$ to provide adequate mixing for polymer solution (polyacrylamide or polyethylene oxide flocculant) and mineral suspension. When polymer addition was complete, agitation was immediately stopped. Flocculant performance was evaluated through batch settling tests in 250-ml graduated cylinders. The partly flocculated slurry was transferred to a graduated cylinder. The calculation of interface settling rates is the same as used in the coagulation tests. All settling tests were conducted in duplicate, thus the results presented in this study are average values.

In addition, some tests with sodium hexametaphosphate were also conducted. Illite suspensions in distilled water and at $1 \mathrm{M} \mathrm{NaCl}$ were mixed with dispersant, sodium hexametaphosphate (NaHMP). Then, polyethylene flocculant was added to observe the effect of the dispersant on flocculation. All settling tests were performed in duplicate; consequently, the results are average values.

\section{Viscosity measurements}

Kinematic viscosity measurements of nonionic and anionic flocculant solutions in distilled water and $\mathrm{NaCl}$ solutions were performed at natural $\mathrm{pH}$ and $\mathrm{pH} 11$. PEO flocculant was evaluated in the concentration range from $140-260 \mathrm{mg} / \mathrm{L}$ while PAM flocculant was tested in the concentration range from $10-115 \mathrm{mg} / \mathrm{L}$. These ranges were selected to be below the critical concentration limit $-\mathrm{c}^{*}=2.5 /[\eta]$ proposed for PAM by Kulicke et al.,[19] and also to assure an exact analysis, relative viscosities were between 1.2 and 2.5 as was recommended by Kulicke and Clasen [20]. Stock flocculant solutions were prepared and left overnight and then 
diluted the next day. These solutions were used within 24 hours. The measurements were made using three Canon-Fenske capillary viscometers (diameter $0.54 \mathrm{~mm}$ ) of different calibration constants. The capillary constant, $\mathrm{K}$, is a specific factor for each capillary. The constants $(0.007475,0.007356$ and 0.007551$)$ that were provided by the manufacturer were recalculated using the literature value of the kinematic viscosity of water at $25^{\circ} \mathrm{C}, 0.8926 \mathrm{~mm}^{2} / \mathrm{s}$ [21]. These tests were carried out with distilled water at $25^{\circ} \mathrm{C}$ and the new constants were $0.007332,0.007143$ and 0.007330 , respectively. The viscometers were cleaned with a $15 \%$ hydrogen peroxide $\left(\mathrm{H}_{2} \mathrm{O}_{2}\right)$ solution and then with a $15 \% \mathrm{HCl}$ solution as recommended by the manufacturer. When $\mathrm{pH} 11$ was needed to be reached, to minimize dilution of the already dilute polymer solutions, the $\mathrm{pH}$ adjustment was effected by the addition of a few drops of $1 \mathrm{M} \mathrm{NaOH}$ solution. 7-ml aliquots of the final dilute flocculant solution were transferred to the capillary viscometer reservoir. The remaining diluted samples were used for measuring $\mathrm{pH}$. Thereafter the viscometer was placed in a water bath whose temperature was maintained constant at $25^{\circ} \mathrm{C}$ for an equilibration time of 30 minutes. The kinematic viscosity was then determined by allowing the flocculant solution to flow down the capillary under gravity. A PVS1 Lauda photo-timing and processing system interfaced with a computer was employed to measure three flow times and the average of these values was used to calculate the kinematic viscosity (in $\mathrm{mm}^{2} / \mathrm{s}$ ). The standard deviation of flow times was always less than 1 second. From the flow times, relative viscosities of the flocculants in distilled water and $\mathrm{NaCl}$ were calculated at each concentration and $\mathrm{pH}$. The equation suggested by Fedors [22] for application to intrinsic viscosity determination of dilute to moderately concentrated solutions was used to fit the data and obtain the intrinsic viscosity values and also to analyzed the effect of $\mathrm{pH}$ and increased electrolyte concentration on the solution viscosities of the flocculants.

\section{Results and discussion}

\section{Zeta potential measurements}

Zeta potential of dolomite particles was measured in distilled water, $10^{-3} \mathrm{M} \mathrm{NaCl}$ and $10^{-2} \mathrm{M} \mathrm{NaCl}$ solutions as a function of $\mathrm{pH}$ (Fig. 2). The reason of the lack of data in an acidic environment is to prevent reaction of this carbonate mineral with the acid $(\mathrm{HCl})$ used to adjust $\mathrm{pH}$. The particles have moderately negative charge in all solutions, as determined by micro-electrophoresis, and no isoelectric point was observed. Similar electrokinetic measurements were reported by Moudgil et al. [23] for three dolomite samples from three different suppliers. Some works, as that of Somasundaran and Agar [24], reported that the principal potential determining species for calcite, another carbonate, are $\mathrm{Ca}^{2+}, \mathrm{HCO}_{3}{ }^{-}, \mathrm{H}^{+}$, and $\mathrm{OH}$. They suggested that the negative zeta potential of dolomite is mainly attributed to the high concentration of negatively charged species such as $\mathrm{HCO}_{3}^{-}$.

There is a slight decrease in the magnitude of zeta potential values when ionic strength is increased. Similarly, to the electrokinetic results obtained in this study, the zeta potential measurements of dolomite in distilled water have been reported and values varied from 0 to $-20 \mathrm{mV}$ [25]. Some researchers have reported values of $\mathrm{pH}_{\text {iep }}$ of pure dolomite around 6 and 8 [25-27], and even in several studies all zeta potential values were found to be positive as a function of $\mathrm{pH}$ [28-30]. What is important here is that, generally, it is considered that for the zeta potential greater than $+20 \mathrm{mV}$ or more negative than $-20 \mathrm{mV}$ the electrostatic repulsion between the particles is larger than the attractive energy and, consequently, such a mineral suspension is stable. Therefore, since the measured zeta potential values for the tested dolomite were smaller than $-20 \mathrm{mV}$ these particles should form slowly coagulating suspensions.

With respect to the electrokinetic measurements of illite (anisotropic mineral), Johnson et al., [31] reported the lack of correlation between the rheological measurements and the electrokinetic measurements for kaolinite suspensions. This discrepancy questions the applicability of Smoluchowski's equation to the calculation of zeta potential from the measured electrophoretic mobility for plate-like anisotropic minerals [32]. For this reason, zeta potential measurements were not performed for illite in this study. 


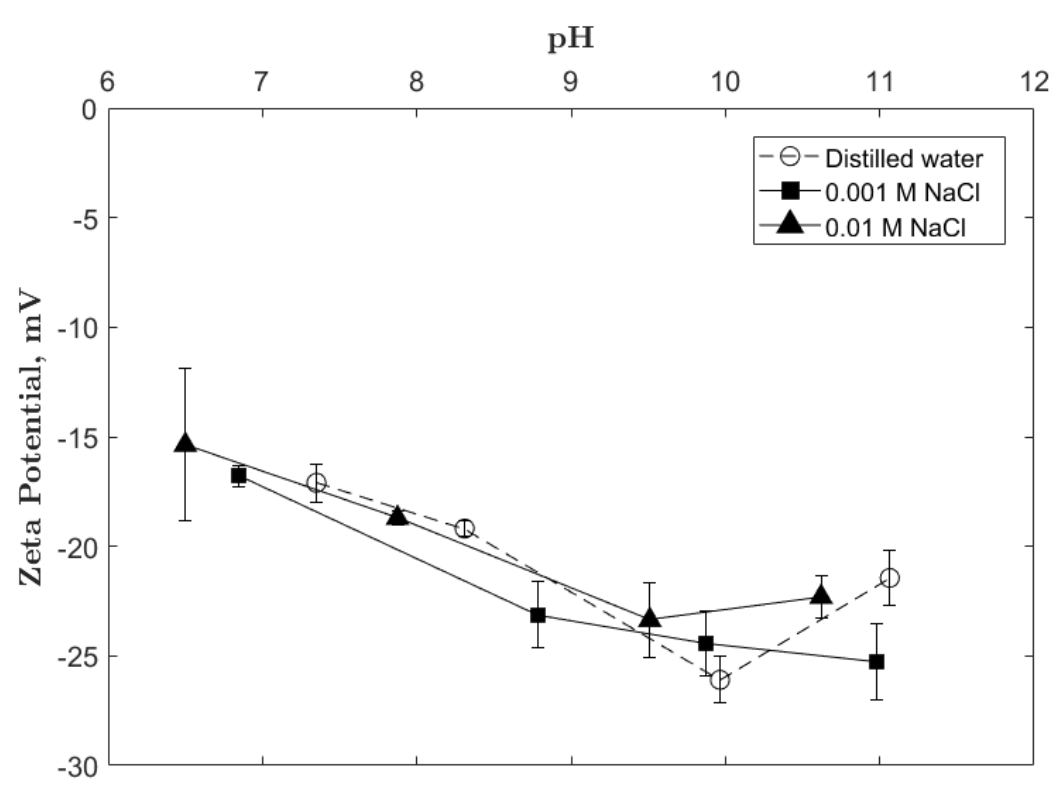

Fig. 2. Zeta potential-pH behavior of dolomite suspensions in distilled water, at $0.001 \mathrm{M} \mathrm{NaCl}$ and $0.01 \mathrm{M}$ $\mathrm{NaCl}$.

\section{Coagulation tests}

As expected, dolomite suspensions in water were found to be unstable (Fig. 3B); this is especially visible when compared with the stability of illite (Fig. 3A). The coagulation results for illite suspensions varying in ionic strength and $\mathrm{pH}$ indicate that these suspensions were stable in distilled water over the $\mathrm{pH}$ range from 6.5 to 11 . The coagulation was becoming visible when ionic strength was increased. This agrees with Tombacz and Szekeres [33], who highlighted that the positive edge negative face interactions lead to coagulation of kaolinite suspensions only above a threshold of electrolyte concentration. A high electrolyte concentration needed to initiate kaolinite coagulation indicates dramatically increased stability of these suspensions in alkaline environment.

While the effect of increased concentration of $\mathrm{NaCl}$ on stability of the tested suspensions was as expected for illite, it turned out to be the opposite for dolomite. These suspensions were found to be more stable in $1 \mathrm{M} \mathrm{NaCl}$ solution than in distilled water. It could be due to $\mathrm{CO}_{3}{ }^{2-}$ ions are also potential determining ions of dolomite and specific adsorption could be responsible for an increase in surface charge and therefore greater stability of the suspension. While illite suspensions were expected to coagulate in acidic solutions and be stable in alkaline environment this was not confirmed by the experiments. 

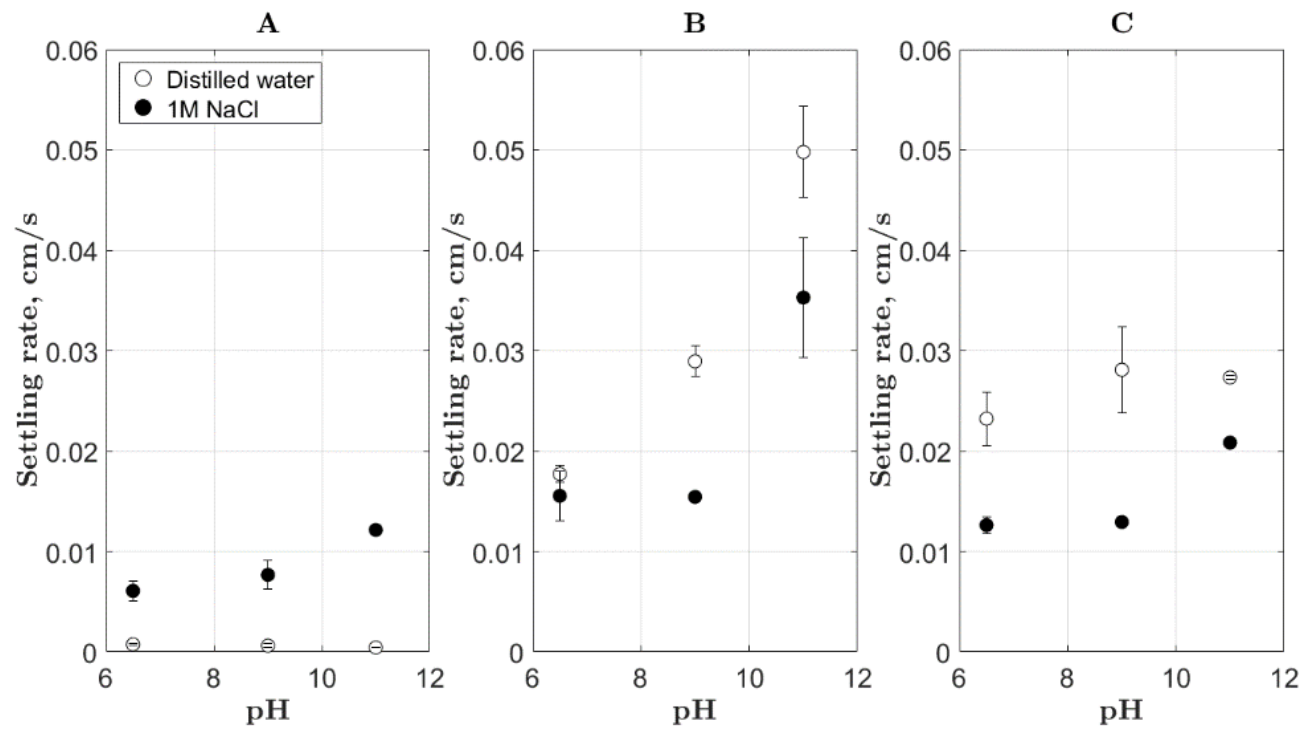

Fig. 3. Effect of $\mathrm{pH}$ on settling rate of (A) illite, (B) dolomite and (C) 50:50 illite-dolomite suspensions in distilled water and at $1 \mathrm{M} \mathrm{NaCl}$.

\section{Flocculation tests}

As was observed in the flocculation tests, flocculating suspensions followed two patterns ( $\mathbf{A}$ and $\mathbf{B}$ ) illustrated in Fig. 4. In the case of A, a clear layer develops after a while, with a definite boundary below it, which is the mudline. The boundary falls rapidly and then more slowly approaching a limiting sediment volume. This provides reproducible settling rates. On the other hand, in the case of $\mathbf{B}$, the fragments built from flocculating particles sediment faster than the non-flocculating fine particles, leading a haze at the top of the settling column. The settling rate results obtained under such conditions are not very reliable and highly irreproducible. Mineral suspensions flocculated by polyacrylamide flocculant emulates case A (Fig. 4), but illite suspensions in distilled water at $\mathrm{pH} 11$ displayed a peculiar behavior (like case $\mathbf{B}$ ) which is explained subsequently. Flocculation in an acidic environment is not good for both illite and dolomite.

A
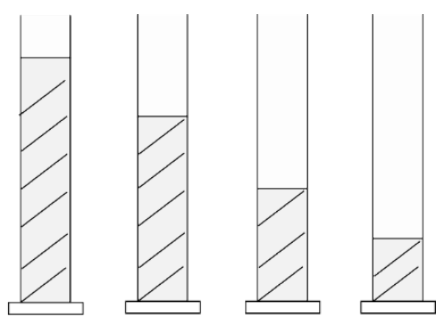

B

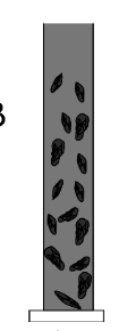

Fig. 4. Visual appearance of flocculated mineral suspensions (schematic): (A) Clear mudline, (B) Undetectable mudline. 
A bell-shaped curve with settling rate vs dosage of PAM is obtained for flocculated illite suspensions in distilled water at pH 9 (Fig. 5A). This confirms that for the hydrophilic macromolecules when they are well extended in a good solvent, at some flocculant dosages, the bridging mechanism is possible and is indicated by a clear optimum on the flocculation curve. At higher polymer concentrations, the polymer-polymer interactions are preferred to polymer-solvent interactions and repulsion appears which stabilizes the suspension. At the $\mathrm{pH}$ range from 9-11, the effect of ionic strength in illite suspensions eliminates the optimum visible in distilled water at $\mathrm{pH} 9$, and flocculation become possible even at higher dosages of the polyacrylamide flocculant where the steric stabilization is observed in distilled water at $\mathrm{pH} 9$.

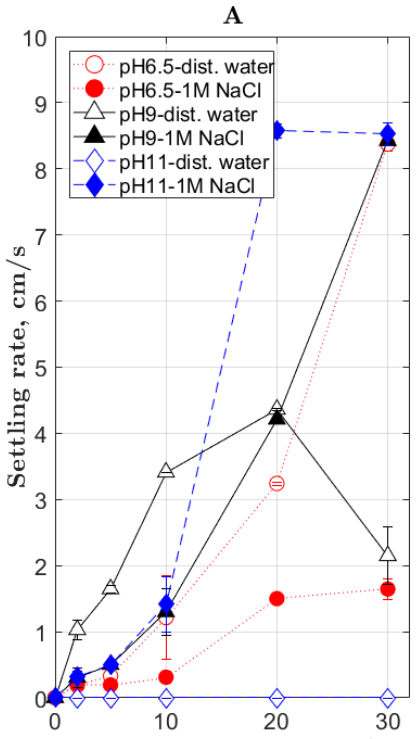

Flocculant dosage, $\mathrm{mg} / \mathrm{L}$

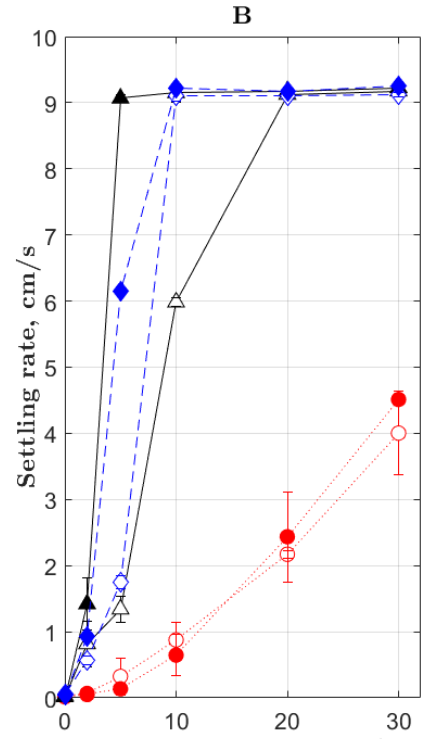

Flocculant dosage, $\mathrm{mg} / \mathrm{L}$

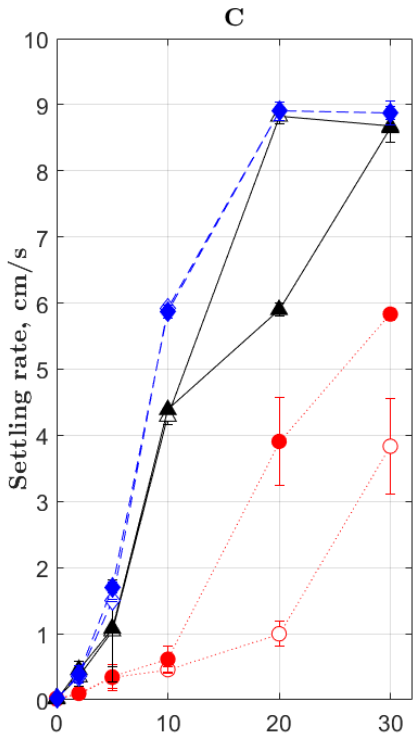

Flocculant dosage, $\mathrm{mg} / \mathrm{L}$

Fig. 5. Effect of A100 polyacrylamide flocculant dosage on settling rate of the (A) illite, (B) dolomite and (C) illite-dolomite suspensions in distilled water and at $1 \mathrm{M} \mathrm{NaCl}$ and varying $\mathrm{pH}$.

The dolomite and 50:50 illite-dolomite suspensions are to some extent unstable toward particle size enlargement with polyacrylamide flocculant, as shown in Fig. 5. At pH of 11 in distilled water, illite does not flocculate with PAM, dolomite does. Consequently, addition of the flocculating dolomite to non-flocculating illite makes the illite-dolomite mixture flocculate. According to settling rate results, the illite-dolomite mixture suspensions demonstrate great dependence on $\mathrm{pH}$, as presented in coagulation results. In all cases the flocculation with PEO at $\mathrm{pH} 6.5$ is poor. The flocculation of clay suspensions by polyethylene flocculant reported higher settling rates in distilled water than those obtained at $1 \mathrm{M} \mathrm{NaCl}$ both at $\mathrm{pH} 9$ and 11 (Fig. 6A). Scheiner and Wilemon [35] reported that PEO is effective in flocculating wastes that contain clay materials. Michaels hypothesizes that the flocculating ability of nonionic and anionic water-soluble polymers is caused by adsorption (via ester formation or hydrogen bonding) of hydroxyl groups or amide groups on the solid particle surface [2].

As shown in Fig. 6, polyethylene oxide does not flocculate dolomite suspensions under the tested conditions $(\mathrm{pH}$, ionic strength and flocculant dosages). At $\mathrm{pH} 11$, addition of flocculating illite to nonflocculating dolomite forces the illite-dolomite mixture to flocculate. 

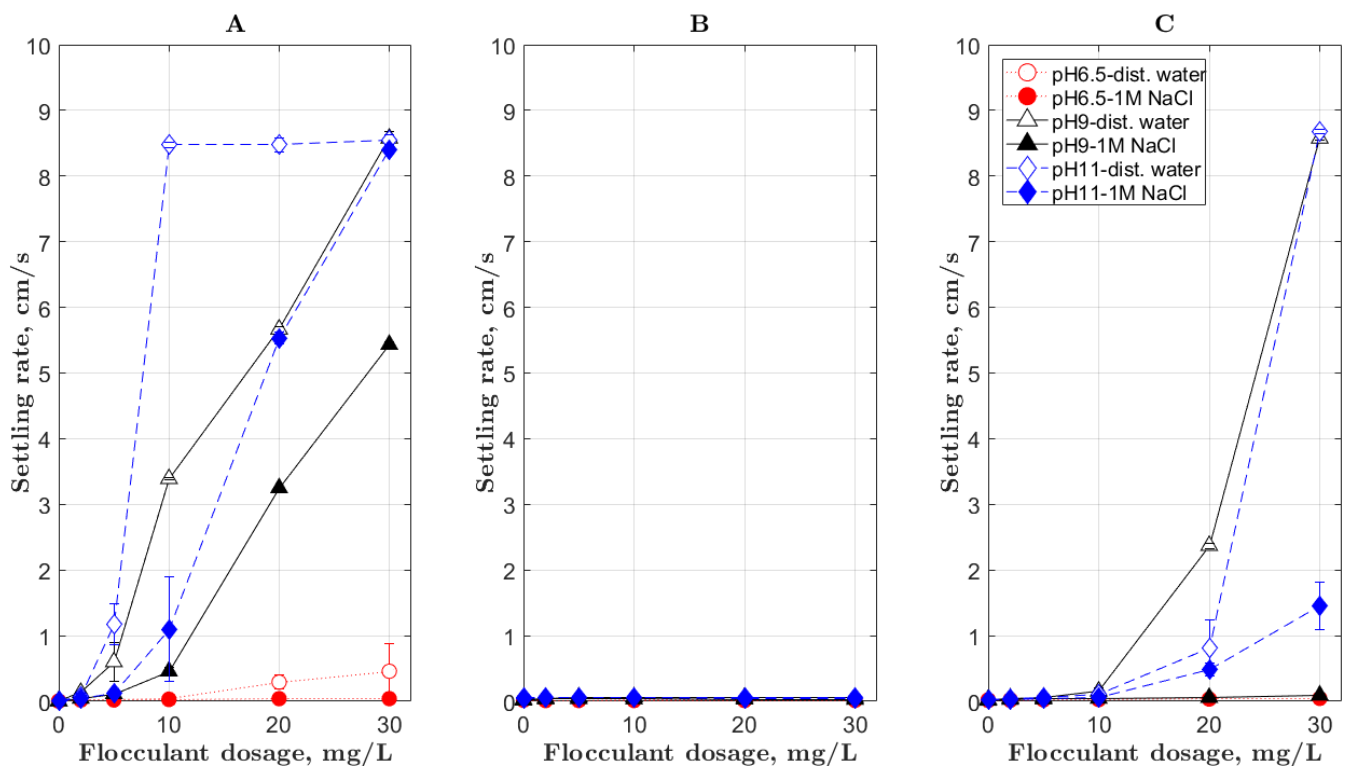

Fig. 6. Effect of polyethylene oxide flocculant dosage on settling rate of illite (A), dolomite (B) and illitedolomite mixture $(\mathbf{C})$ in distilled water and at $1 \mathrm{M} \mathrm{NaCl}$ and varying $\mathrm{pH}$.

At high dosage of the flocculant $(30 \mathrm{mg} / \mathrm{L})$ the flocculation of the mixture can be quite good. However, it was observed that the mixture suspensions flocculated by PEO at the highest flocculant dosage used in this study exhibited significantly high turbidity and this is explained by the case $\mathbf{B}$ displayed in Fig. 4. Particularly, it suggests that PEO selectively flocculated illite, and non-flocculating dolomite particles remained localized in the supernatant.

The effect of $\mathrm{pH}$ and $\mathrm{NaCl}$ concentration on flocculation of illite and dolomite suspensions by PAM and PEO is shown in Fig. 7. Comparison of these two plots indicates that PAM is a much better flocculant, in that it flocculates both tested minerals and their mixture. Effectiveness of PAM significantly decreases in acidic conditions both in distilled water and in $1 \mathrm{M} \mathrm{NaCl}$ solution; moreover, this happens despite the extended configuration of PAM macromolecules in acidic solutions (as suggested by the intrinsic viscosity measurements). In the case of illite at $\mathrm{pH} 11$, the particles are negatively charged, and this may stabilize illite suspension against coagulation but also may affect PAM adsorption. As reported by Sworska et al.,[36] the presence of $\mathrm{Mg}^{2+}$ and $\mathrm{Ca}^{2+}$ ions can significantly improve flocculation of kaolinite in alkaline solutions. The discussed figure also shows that dolomite is not flocculating with PEO at all. The poor flocculation of dolomite suspensions was observed both in acidic and alkaline solutions, and both in distilled water and $1 \mathrm{M} \mathrm{NaCl}$ solution. That indicates that conformation of the PEO macromolecules is not the reason in this case. The likely reason is poor adsorption of PEO onto dolomite. Rubio and Kitchener [37] suggested that adsorption of PEO on silica may be due to isolated silanol groups and/or hydrophobic sites on silica. Moudgil and Chanchani [38] floated dolomite as a function of oleate concentration. For this reason, in this work, several experiments with addition of sodium oleate to render dolomite surface hydrophobic were carried out but no improvement in the flocculation rate of this carbonate with PEO was observed, these results are not included in this study. Moudgil et al. [39] determined that the flocculation of a dolomite sample by PEO was associated with the presence of minor amounts of palygorskite a Mg-rich clay which modifies the surface chemical behavior of the dolomite sample. The isolated-OH groups hydrogen- bond with the ether oxygen of PEO and result in flocculation of palygorskite and dolomite. Mathur and Moudgil's [40] study revealed that the simple presence of isolated hydroxyls on oxide surfaces does not necessarily result in adsorption of PEO. 

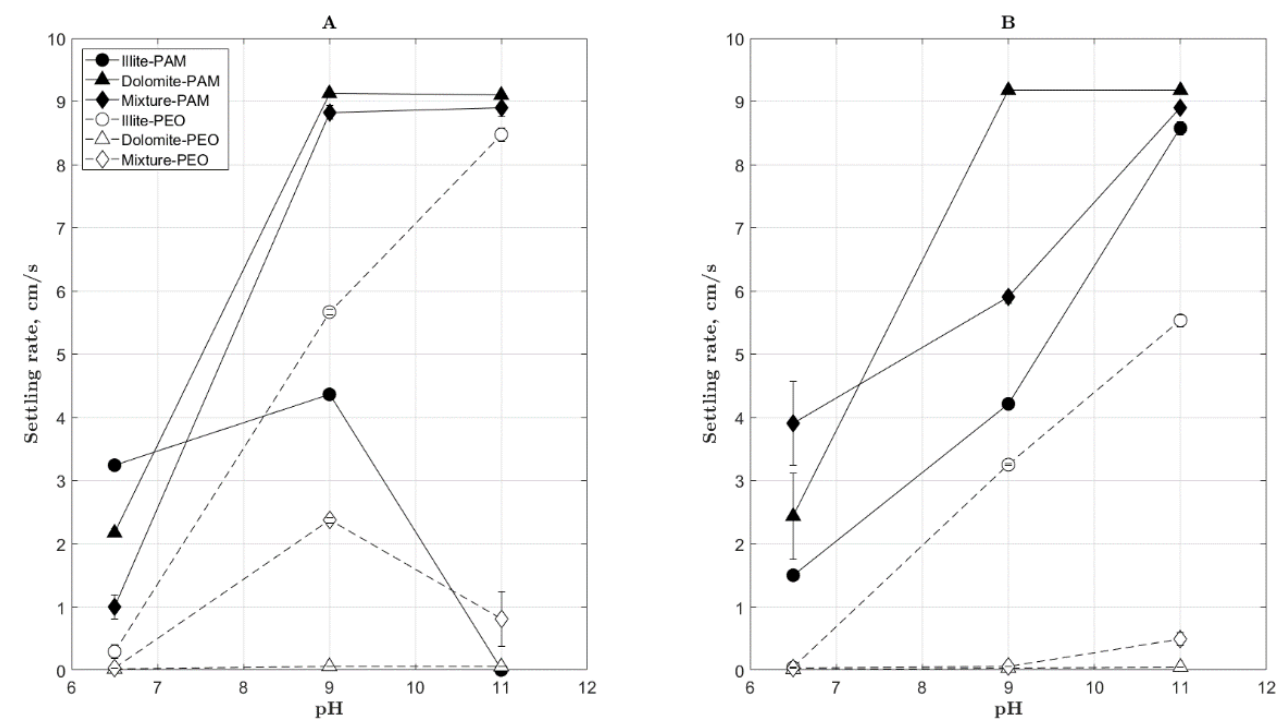

Fig. 7. Effect of concentration of potential determining ions $(\mathrm{pH})$ in distilled water $(\mathbf{A})$ and $1 \mathrm{M} \mathrm{NaCl}$ solutions (B) on flocculation by PAM and PEO at $20 \mathrm{mg} / \mathrm{L}$ dosage.

Fig. 8 confirms the effect of sodium hexametaphosphate (NaHMP) as a dispersant of clay minerals. It is shown there that addition of NaHMP decreases the flocculation rates of illite suspensions over the $\mathrm{pH}$ range from 9 to 11. Ramirez et al.,[41] evaluated the effect of sodium hexametaphosphate in the flotation of chalcopyrite in the presence of kaolinite in sea water over the $\mathrm{pH}$ range from 7 to 11 and reported that this clay dispersant depresses kaolinite under such conditions. The preceding statement corroborates the results obtained in this work. According to Andreola et al.,[42] NaHMP accomplishes its dispersing action through a combined mechanism: (i) by increasing the overall negative surface charge, especially at the edges of the clay mineral particles; (ii) by increasing the thickness of the electrical double layer. Despite sodium hexametaphosphates functionality as a clay dispersant, NaHMP unexpectedly improved settling rates of illite suspensions flocculated by PEO at $\mathrm{pH} 6.5$ and this fact cannot be explained at this stage.

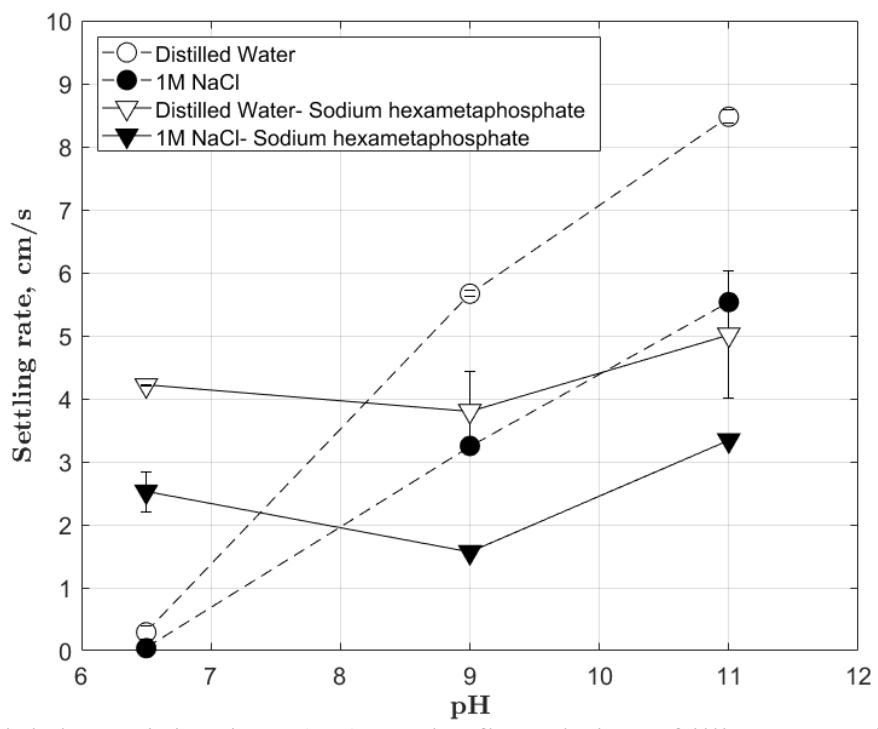

Fig. 8. Effect of potential determining ions $(\mathrm{pH})$ on the flocculation of illite suspensions by PEO $(20 \mathrm{mg} / \mathrm{L})$ with and without Sodium Hexametaphosphate $(1 \mathrm{~g} / \mathrm{L})$. 


\section{Intrinsic viscosity measurements}

The conformation of flocculant macromolecules in solution can be studied through intrinsic viscosity measurements. Viscosity measurements may be reported in several forms such as dynamic viscosity $\eta$, relative viscosity $\eta r=\eta / \eta s$, specific viscosity $\eta s p=(\eta-\eta s) / \eta s=\eta r-1$, reduced vlscosity $\eta$ red(c) $=\eta s p / c$ and intrinsic viscosity $[\eta]$. In these expressions $\eta \mathrm{s}$ is the solvent viscosity, $\mathrm{c}$ is the polymer solution concentration. The intrinsic viscosity is defined as the reduced viscosity when the concentration $\mathrm{c}$ tends to zero and its unit is [ $\left.\mathrm{c}^{-1}\right]$, usually given as $[100 \mathrm{ml} / \mathrm{g}=\mathrm{dL} / \mathrm{g}]$. The behaviour of polymers in salt solutions is commonly analyzed using the macromolecule-solvent interaction $\chi$ parameter usually referred to as the Flory-Huggins parameter. Perhaps one of the simplest way of assessing the $\chi$ parameter is via intrinsic viscosity measurements [43]. The flow time between two fixed marks in a capillary tube, $t$, for the solution and the solvent is inversely proportional to the density, $\rho$, and proportional to the viscosity, $\eta[20]$.

$$
t_{\text {solution }}=\text { constant } \frac{\eta_{\text {solution }}}{\rho_{\text {solution }}} ; t_{\text {solvent }}=\text { constant } \frac{\eta_{\text {solvent }}}{\rho_{\text {solvent }}}
$$

The relative viscosity $(\eta \mathrm{r})$ is defined as the ratio $\eta$ solution/ $\eta$ solvent. For very small polymer concentrations, the assumption is that the density of the dilute polymer solution psolution equals the density of the pure solvent $\rho$ solvent. Therefore, the relative viscosity is a simple ratio:

$$
\eta_{r}=\frac{t_{\text {solution }}}{t_{\text {solvent }}}
$$

intrinsic viscosity $[\eta]$ is a measure of the inherent ability of a polymer to increase solution viscosity. It is evaluated by extrapolation of experimental data to zero concentration to eliminate polymer intermolecular interactions and can also be estimated from the reciprocal of the slope of the line of best fit to the experimental data using Fedors equation. Accordingto Fedors [22] for uncharged polymers:

$$
\frac{1}{\left(2\left(\eta_{r}^{(1 / 2)-1}\right)\right)}=\frac{1}{([\eta] c)}-\frac{1}{\left([\eta] c_{m}\right)}
$$

where $\eta \mathrm{r}$ is the relative viscosity at $\mathrm{c}$ (polymer concentration) and $\mathrm{cm}$ is a polymer concentration parameter. A plot of the quantity versus $1 /\left(2\left(\eta_{\mathrm{r}}^{(1 / 2)-1}\right)\right)$ versus $1 / \mathrm{c}$ should result in linear response with slope equal to $1 /([\eta])$ and intercept $1 /([\eta] \mathrm{cm})$. The intrinsic viscosity is determined by calculating the inverse of the slope. In this study a linear interpolation was used to obtain the slope of each plot and R-squared (R2) values were above 0.90 meaning good linear fits.

As pointed out by Gochin et al.,[44] for non-ionic polymers electrolyte concentration does not change the conformational state of the macromolecules and this entirely agrees with the results shown in Fig. 9. The solubility of this polymer in water results from hydrogen bonding and these macromolecules are always in the extended form provided that the temperature is kept constant (increased temperature reduces hydrogen bonding between the polymer macromolecules and water and decreases PEO solubility) [45]. The situation of anionic PAM is very different; it is in the extended state in distilled water and any increase in ionic strength causes coiling of the PAM macromolecules (as shown by decreasing intrinsic viscosity Fig. 9). It indicates that the carboxylic groups seem to be sufficiently dissociated at natural $\mathrm{pH}$, as shown by the highest intrinsic viscosities. The results also indicate excellent solvation of the polymer chains by water and this makes possible chain extension.

When the $\mathrm{pH}$ is increased to approximately 11 in distilled water, there is a pronounced decrease in the intrinsic viscosity for anionic flocculant. Therefore, the most likely explanation for this reduction is that at high $\mathrm{pH}$ due to $\mathrm{NaOH}$ addition the charge on the ionized carboxylic groups is neutralized by the counterions. When the anionic polyacrylamide flocculant is tested in $\mathrm{NaCl}$ solutions $(0.01 \mathrm{~mol} / \mathrm{L}$ and $1 \mathrm{~mol} / \mathrm{L})$ there is a coiling of the macro- molecules which is reflected in a marked decrease in intrinsic viscosity values. An interesting 
observation is the one-fold increase of the intrinsic viscosity of A100 when the electrolyte concentration is increased from $0.01 \mathrm{M}$ to $1 \mathrm{M} \mathrm{NaCl}$.

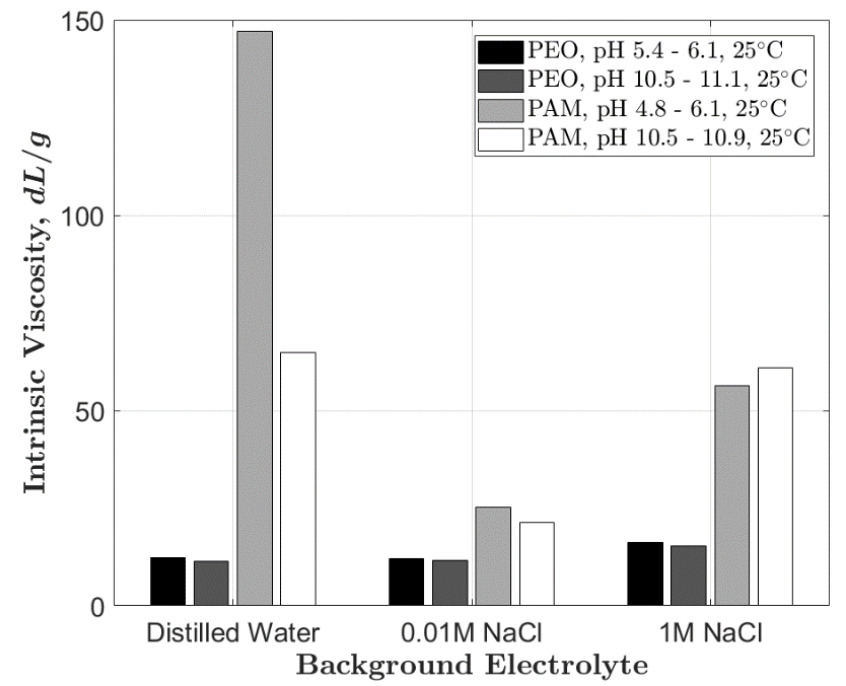

Fig. 9. Effect of $\mathrm{pH}$ and electrolyte concentration on the intrinsic viscosity of nonionic flocculant (PEO) and anionic polyacrylamide flocculant (PAM) at $25^{\circ} \mathrm{C}$.

Due to the polyelectrolyte effect, Hug-gins equation which was originally derived for dilute solutions of nonionic polymers cannot be used to measure intrinsic viscosities of anionic polymers. However, this equation was employed to illustrate the effects of solvency of sodium chloride solutions for polyacrylamide macromolecules. According to the Huggins equation [46]:

$$
\eta_{\text {red }}=[\eta]+k\left[\eta^{2}\right] c
$$

where $\eta_{\text {red }}$ is the reduced viscosity $((\eta \mathrm{r}-1) / \mathrm{c}),[\eta]$ is the intrinsic viscosity, $\mathrm{c}$ is the polymer concentration, and $\mathrm{k}$ is the Huggins coefficient which is dimensionless. A plot of $\eta_{\text {red }}$ vs c should yield a straight line with the intercept equal to $[\eta]$. Therefore, the Huggins coefficient can be calculated from the slope values.

Sakai [47] has reported that the values of k may vary between 0.5 and 0.7 for a polymer under thetaconditions which promotes polymer-polymer interactions over polymer-solvent interactions. This is the transition from a good solvent to a poor solvent. Generally, a polymer exhibits a higher value of $\mathrm{k}$ in a poor solvent than in a good solvent.

Furthermore, this coefficient is very sensitive to the formation of molecular aggregates. In a few words, the solvency power of the solvents plays an important role with coil dimensions being the largest in good solvents; in addition, intrinsic viscosity measurements are a convenient way of estimating solvency effects.

The solid lines of Fig. 10 are trend lines, while the dashed lines show the linear fits (Huggins equation) to the experimental data in $0.01 \mathrm{M} \mathrm{NaCl}$ solutions over the tested poly- acrylamide concentration range at $\mathrm{pH}$ 6 and 11 (Table 2). The intrinsic viscosity results of A100 PAM in $0.01 \mathrm{M} \mathrm{NaCl}$ solutions at pH 6 and 11 and at $25^{\circ} \mathrm{C}$ agree with the already published values by Arinaitwe and Pawlik [48].

As Fig. 10 and Table 2 indicate, $0.01 \mathrm{M} \mathrm{NaCl}$ solutions seem to be a worse-than-theta solvent $(\mathrm{k}$ is greater than $0.5-0.7$ ) for the anionic polyacrylamide flocculant. Unexpectedly the overall relationship between the reduced viscosity and PAM concentration in $1 \mathrm{M} \mathrm{NaCl}$ solutions assumes a polynomial function with respect to the polymer concentration c. As reported by Napper [49], the simplest way to bring about instability in sterically stabilized dispersions is to reduce the solvency of the dispersing medium for the stabilizing species. 
It is reasonable to expect that high concentrations of hydrated $\mathrm{Na}^{+}$ions bind large amounts of water molecules leaving no free water for the anionic polyacrylamide hydration and dissolution [50]. Hence, it induces intermolecular association between coiling PAM macromolecules which may increase the intrinsic viscosity as shown in Fig. 9 in which there is a one-fold increase of the intrinsic viscosity of A100 when the electrolyte concentration is increased from $0.1 \mathrm{M}$ to $1 \mathrm{M} \mathrm{NaCl}$. Consequently, it may lead to incipient flocculation where adsorbed layers of polyacrylamide are aggregated, and this is supported by the quite good results obtained in the flocculation of illite suspensions with PAM in $1 \mathrm{M} \mathrm{NaCl}$ solutions over the $\mathrm{pH}$ range from 9 to 11 (as shown in Fig. 5A).

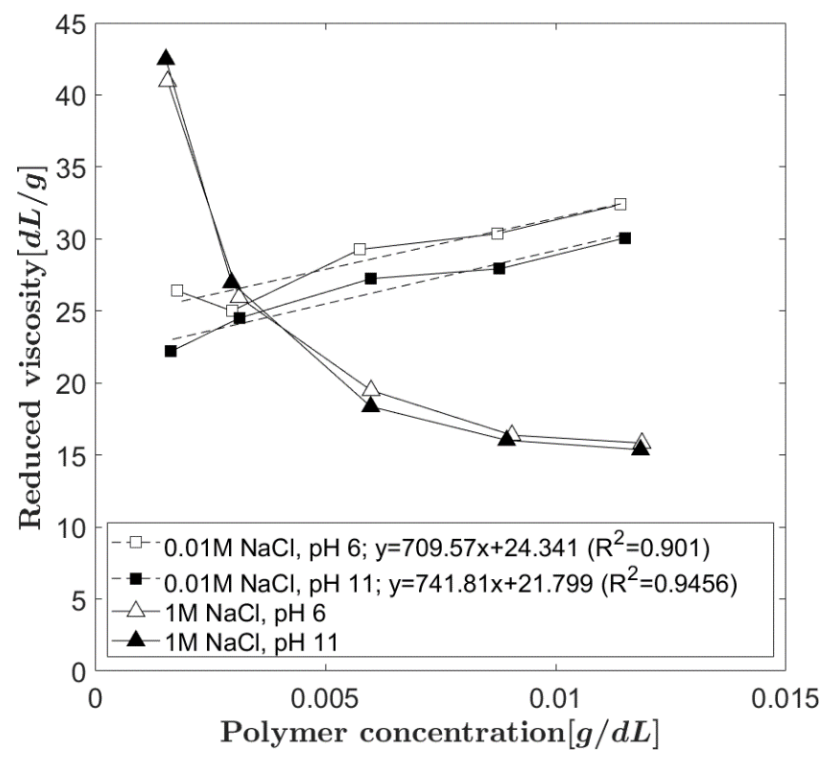

Fig. 10. Reduced viscosity vs PAM concentration for different sodium chloride solutions and $\mathrm{pH}$ at $25^{\circ} \mathrm{C}$.

Table 2. Linear fit (Eq. (4)) parameters for $0.01 \mathrm{M} \mathrm{NaCl}$ solutions.

\begin{tabular}{|c|c|c|c|}
\hline $\mathbf{p H}$ & Slope, $\mathbf{k}$ & Intercept, & Huggins coefficient, $\mathbf{k}$ \\
\hline 6 & 709.57 & 24.34 & 1.20 \\
\hline 11 & 741.81 & 21.78 & 1.56 \\
\hline
\end{tabular}

The effect of $\mathrm{pH}$ on the intrinsic viscosities at constant ionic strength is not dramatic. The presence of background ions rather than $\mathrm{pH}$ seems to be the prevailing factor in determining the conformation of PAM, as reported by Arinaitwe [18]. In addition, the anionic flocculant seems to be more flexible than the nonionic flocculant in terms of its ability to coil or stretch as shown by the significant decrease of PAM's intrinsic viscosity when tested at increased ionic strength.

The results of intrinsic viscosities using Fedors equation are in agreement with those reported by Rao [51], Ghimici and Popescu [52] and Arinaitwe [18] which indicate the applicability of this equation for describing not only the viscosity of nonionic flocculants but also the viscosity of polyelectrolyte solutions.

\section{Conclusion}

For a polymeric flocculant to bring about bridging flocculation, it is necessary for its macro- molecules not only to adsorb onto the surface of the particles, but also for the loops and tails of the adsorbed chains to 
extend or stretch further into the dispersing medium. This is possible if the macromolecules adopt an extended configuration. This is determined not only by the molecular weight but also by electrical charge and hydration of the macromolecules. In the case of ionic flocculants at high ionic strength, shielding of the charge produces a more compact configuration; hence, reducing the possibility of bridging. It is worth mentioning that at very high salt concentrations, the medium would tend to become a worse solvent for polymeric compounds and may tend to salt out the polymer.

As viscosity tests demonstrate, while conformational properties of PAM macromolecules are very sensitive to ionic strength (Fig. 9), the conformation state of PEO is not influenced by electrolyte concentration. These macromolecules adopt rather coiled configuration irrespective of $\mathrm{pH}$ and concentration of $\mathrm{NaCl}$ (Fig. 9). Furthermore, as the intrinsic viscosity results show, polyacrylamide is coiled at high salt concentrations, and this conformation should prevent bridging flocculation. At the same time, high $\mathrm{pH}$ (9-11) promotes strong dispersion of illite particles. In other words, flocculation of illite by $\mathrm{PAM}$ at high $\mathrm{pH}$ and high salt concentrations should be very difficult. However, it is obvious that flocculation of illite under those conditions is the most pronounced of all the tested conditions (Fig. 5A). In this case, attraction between coiled polyacrylamide molecules adsorbed on individual mineral particles seems to drive the flocculation process at high salt concentrations. This process differs from flocculation by bridging. In bridging flocculation, extended flocculant chains adsorb on several particles at the same time and, since the bridging flocculation process takes place in good solvent conditions, attraction between extended flocculant chains is very weak. Bridging by adsorbed polymer chains should be the prevailing mechanism at low salt concentrations and under good solvent conditions. Moreover, the results of flocculation tests with PEO, shown in Fig. 6, demonstrate that illite is flocculated very well at $\mathrm{pH} 9$ and 11 but not at $\mathrm{pH}$ of 6.5. Illite-dolomite mixture behaves correspondingly; in addition, its flocculation is negligible at slightly acidic conditions. Dolomite is not flocculated by PEO under any tested conditions. Since these differences cannot be explained by different conformation of PEO in distilled water or salt solutions, the reason for very poor flocculation of this carbonate must result from poor adsorption of PEO onto dolomite particles. Additionally, Fig. $6 \mathrm{C}$ seems to indicate that the flocculation of the illitedolomite mixture is predominantly by flocculating illite and may be selective.

The PAM flocculant, in comparison with PEO, appears to be less selective and flocculates very well both tested minerals (including the mixture). It flocculates dolomite better than illite. Both minerals flocculate better in alkaline solutions and exhibit less efficient flocculation at $\mathrm{pH} 6.5$; thus, the illite-dolomite mixture presents the same effect as the individual mineral suspensions. In general, dolomite suspensions are less stable than illite and it is confirmed via electrokinetic measurements and coagulation tests; however, their higher stability in $1 \mathrm{M} \mathrm{NaCl}$ solutions cannot be explained at this stage. It is difficult in both tested cases with PAM and PEO to determine any relationship between coagulation and flocculation.

\section{Acknowledgements}

Financial support for this study from the Secretariat of Higher Education, Science, Technology and Innovation of Ecuador (SENESCYT) is gratefully acknowledged.

\section{References}

1. Laskowski, J. S., in: Coal Flotation and Fine Coal Utilization, Elsevier Science B.V., 2001.

2. Michaels, A. S. Ind. Engnineering Chem. Chem. 1954, 46, 1485-1490. DOI: https://doi.org/10.1021/ie50538a053.

3. Hogg, R., Polymer Adsorption and Flocculation. Polymers in Mineral Processing - Proc. of the Third UBC-McGill International Symposium on Fundamentals of Mineral Processing; Laskowski, J. S., Ed.; Metallurgical Society of CIM: Quebec City, 1999; pp 3-18.

4. Attia, Y. A. Flocculation. In Colloid chemistry in mineral processing; Laskowski, J. S., Ralston, J., Eds.; Elsevier Science Publishers B.V., 1992; pp 277-308. 
5. Arinaitwe, E.; Pawlik, M. Int. J. Miner. Process. 2009, 91, 50-54. DOI: https://doi.org/10.1016/j.minpro.2008.12.002.

6. Mpofu, P.; Addai-mensah, J.; Ralston, J. Int. J. Miner. Process. 2003, 71, 247-268. DOI: https://doi.org/10.1016/S0301-7516(03)00062-0.

7. Nasser, M. S.; James, A. E. Sep. Purif. Technol. 2006, 52, 241-252. DOI: https://doi.org/10.1016/j.seppur.2006.04.005.

8. Addai-Mensah, J. Powder Technol. 2007, 179, 73-78. DOI: https://doi.org/10.1016/j.powtec.2006.11.008.

9. Kitchener, J. A. Br. Polym. J. 1972, 4, 217-229. DOI: https://doi.org/10.1002/pi.4980040307.

10. Hogg, R. Coal Preparation Wastewater and Fine Refuse Treatment. In Fine Coal Processing; Noyes Publications, 1987; 269-293.

11. Onen, V.; Gocer, M. Part. Sci. Technol. 2018, 1-8. DOI: https://doi.org/10.1080/02726351.2018.1454993.

12. Rubio, J. Colloids and Surfaces. 1981, 3, 79-95. DOI: https://doi.org/10.1016/0166-6622(81)800352.

13. Laskowski, J.; Castro, S. Int. J. Miner. Process. 2015, 144, 50-55. DOI: https://doi.org/10.1016/j.minpro.2015.09.017.

14. Ferrera, V.; Arinaitwe, E.; Pawlik, M. A Role of Flocculant Conformation in the Flocculation Process. In Proceedings of the 7th UBC-McGill-UA Symposium on Fundamentals of Mineral Processing; Gomez, C. O., Nesset, J. E., Rao, S. R., Eds.; Montreal, 2009; 397-408.

15. Friend, J. P.; Kitchener, J. A. Chem. Eng. Sci. 1973, 28, 1071-1080. DOI: https://doi.org/10.1016/0009-2509(73)80010-7.

16. Huang, P.; Laskowski, J. S.; Zeng, H.; Lu, Q. Use of Flocculants in High Ionic Strength Process Waters. In 9th UBC-McGill-UA Int. Symposium; 2013.

17. Yu, K. Lab Report: Flocculation with the Use of Polyacrylamide as a Flocculant in NaCl Solutions; Vancouver, 2015.

18. Arinaitwe, E. Characterization of Industrial Flocculants Through Intrinsic Viscosity Measurements, MASc Thesis. The University of British Columbia, Canada, 2008. DOI: https://doi.org/10.14288/1.0066521.

19. Kulicke, W.-M.; Kniewske, R.; Klein, J. Prog. Polym. Sci. 1982, 8, 373-468.

20. Kulicke, W.-M.; Clasen, C. Viscosimetry of Polymers and Polyelectrolytes; Springer, Berlin, Heidelberg, 2004. DOI: https://doi.org/10.1002/pi.1722.

21.Lide, D. R. CRC Handbook of Chemistry and Physics, 88th ed.; CRC Press, 2007. DOI: https://doi.org/10.4324/9781410610348.

22. Fedors, R. F. Polymer (Guildf). 1979, 20, 225-228. DO: https://doi.org/10.1016/0032-3861(79)90226$\mathrm{X}$.

23. Moudgil, B. M.; Mathur, S.; Behl, S. Miner. Metall. Process. 1995, 24-27.

24. Somasundaran, P. J. Colloid Interface Sci. 1967, 24, 433-440. DOI: https://doi.org/10.1016/00219797(67)90241-X.

25. Marouf, R.; Marouf-Khelifa, K.; Schott, J.; Khelifa, A. Microporous Mesoporous Mater. 2009, 122, 99-104. DOI: https://doi.org/10.1016/j.micromeso.2009.02.021.

26. Gence, N.; Ozbay, N. Appl. Surf. Sci. 2006, 252, 8057-8061. DOI: https://doi.org/10.1016/j.apsusc.2005.10.015.

27. Pokrovsky, O. S.; Schott, J.; Thomas, F. Geochim. Cosmochim. Acta. 1999, 63, 3133-3143. DOI: https://doi.org/10.1016/S0016-7037(99)00240-9.

28. Liu, Y.; Liu, Q. Miner. Eng. 2004, 17, 865-878. DOI: https://doi.org/10.1016/j.mineng.2004.03.007. 
29. Ding, K.; Laskowski, J. S. Can. Metall. Q. 2006, 45, 199-206. DOI: https://doi.org/10.1179/cmq.2006.45.2.199.

30. Kasha, A.; Al-Hashim, H.; Abdallah, W.; Taherian, R.; Sauerer, B. Colloids Surfaces A Physicochem. Eng. Asp. 2015, 482, 290-299. DOI: https://doi.org/10.1016/j.colsurfa.2015.05.043.

31. Johnson, S. B.; Franks, G. V.; Scales, P. J.; Boger, D. V.; Healy, T. W. Int. J. Miner. Process. 2000, 58, 267-304. DOI: https://doi.org/10.1016/S0301-7516(99)00041-1.

32. Laskowski, J. S. CIM J. 2012, 3, 203-214.

33. Tombácz, E.; Szekeres, M. Appl. Clay Sci. 2006, 34, 105-124. DOI: https://doi.org/10.1016/j.clay.2006.05.009.

34. Hogg, R. Int. J. Miner. Process. 2000, 58, 223-236. DOI: https://doi.org/10.1016/S03017516(99)00023-X.

35. Scheiner, B. J.; Wilemon, G. M. Applied Flocculation Efficiency: A Comparison of Polyethylene Oxide and Polyacrylamides. In Flocculation in Biotechnology and Separation Systems; Attia, Y. A., Ed.; Elsevier Science Publishers B.V.: Amsterdam, 1987; Vol. 4, 175-185.

36. Sworska, A.; Laskowski, J. S.; Cymerman, G. Int. J. Miner. Process. 2000, 60, 143-152. DOI: https://doi.org/10.1016/S0301-7516(00)00012-0.

37. Rubio, J.; Kitchener, J. A. J. Colloid Interface Sci. 1976, 57, 132-142. DOI: https://doi.org/10.1016/0021-9797(76)90182-X.

38. Moudgil, B. M.; Chanchani, R. Trans. Am. Inst. Mining, Metall. Pet. Eng. 1985, 278 (March 1983), $13-19$.

39. Moudgil, B. M.; Mathur, S.; Behl, S. Miner. Metall. Process. 1995, 12, 219-224.

40. Mathur, S.; Moudgil, B. Miner. Metall. Process. 1998, 15, 24-28.

41. Ramirez, A.; Rojas, A.; Gutierrez, L.; Laskowski, J. S. Miner. Eng. 2018, 125 (November 2017), 10 14. DOI: https://doi.org/10.1016/j.mineng.2018.05.008.

42. Andreola, F.; Castellini, E.; Ferreira, J. M. F.; Olhero, S.; Romagnoli, M. Appl. Clay Sci. 2006, 31, 5664. DOI: https://doi.org/10.1016/j.clay.2005.08.004.

43. Pawlik, M.; Laskowski, J. S.; Ansari, A. J. Colloid Interface Sci. 2003, 260, 251-258. DOI: https://doi.org/10.1016/S0021-9797(02)00225-4.

44. Gochin, R. J.; Leklll, M.; Shergold, H. L. Coal Prep. 1985, 2 (May 2012), 19-33. DOI: https://doi.org/10.1080/07349348508905150.

45. Mpofu, P.; Addai-Mensah, J.; Ralston, J. J. Colloid Interface Sci. 2004, 271, 145-156. DOI: https://doi.org/10.1016/j.jcis.2003.09.042.

46. Huggins, M. L. J. Am. Chem. Soc. 1942, 64, 2716-2718. DOI: https://doi.org/10.1021/ja01263a056.

47. Sakai, T. J. Polym. Sci. 1968, 6, 1535-1549.

48. Arinaitwe, E.; Pawlik, M. Int. J. Miner. Process. 2013, 124, 50-57.

49. Napper, D. H. J. Colloid Interface Sci. 1977, 58, 390-407. DOI: https://doi.org/10.1016/00219797(77)90150-3.

50. Ma, X.; Pawlik, M. Can. Metall. Q. 2007, 46, 321-327. DOI: https://doi.org/10.1179/cmq.2007.46.3.321.

51. Rao, M. V. S. Polymer (Guildf). 1993, 34, 592-596. DOI: https://doi.org/10.1016/00323861(93)90555-O.

52. Ghimici, L.; Popescu, F. Eur. Polym. J. 1998, 34, 13-16. DOI: https://doi.org/10.1016/S00143057(97)00072-4. 